\title{
The mangled extremity: assessment, decision making and outcomes
}

\author{
Martin SHARROCK
}

From the School of Surgery, North West Deanery, Manchester, UK

The management of the mangled extremity continues to pose a significant challenge for orthopaedic trauma surgeons. This article provides a comprehensive, up-to-date literature review on the assessment of complex limb injuries, and the variables that affect decision-making and outcomes in both limb salvage and amputation. Initial assessment involves using a systematic approach, saving life before limb, with early involvement of the relevant surgical specialities and multidisciplinary team. The decision to attempt limb salvage or perform amputation can be extremely difficult. Scoring systems can be used as a guide but should not be wholly relied upon; instead more emphasis should be placed on the surgeon's experience, extent of soft tissue damage, and patient factors and wishes. Outcomes following amputation versus limb salvage are comparable, with some studies suggesting amputation may be favourable. It is important to advise patients and families on what treatment is in their best interest so they can make an informed decision, and this must utilise a multidisciplinary approach.

Keywords: Mangled extremity; amputation; limb salvage; decision making.

\section{INTRODUCTION}

The management of complex limb injuries continues to pose a significant challenge for orthopaedic trauma surgeons. A mangled extremity is a limb with severe disruption to bone, nerve, muscle, vasculature and/or soft tissues $(1,2)$, and surgeons

No benefits or funds were received in support of this study. None of the authors have a conflict of interest. are often faced with the difficult decision whether to amputate or attempt limb salvage.

Managing such complex cases requires a multidisciplinary approach. Advances in emergency department resuscitation, vascular reconstruction, plastic surgery soft tissue care and orthopaedic skeletal fixation means that limb salvage is an option for limbs that would historically have required amputation. Despite this, debate still exists as to which limbs benefit from limb salvage and which require primary amputation.

This article reviews the assessment of complex limb injuries, and the variables that affect decisionmaking and outcomes in both limb salvage and amputation.

\section{ASSESSMENT OF COMPLEX LIMB INJURIES}

Complex limb injuries are often caused by a significant mechanism of injury, such as road traffic and industrial accidents, falls from height, gun shots and explosions. Given the high energy transfer involved patients may be multiply injured and must be assessed by Advanced Trauma Life Support (3) principles saving 'life before limb',

Martin Sharrock, MBChB, BSc, MSc, MRCS

School of Surgery, North West Deanery, Manchester, UK

Correspondence : Martin Sharrock, School of Surgery, North

West Deanery, Manchester, UK.

Email : martin.sharrock@doctors.org.uk

- 2021, Acta Orthopædica Belgica. 
utilising a primary and secondary survey. During and following stabilisation, the British Orthopaedic Association Standards for Trauma (BOAST) should be adhered to; these include guidelines on managing open fractures, arterial injuries and peripheral nerve injuries (4-6).

A thorough examination of neurovascular status should be performed, including motor and sensory function of the major nerves of the injured limb. Assessment of pulses and capillary refill time is essential, and adjuncts such as the hand-held Doppler and ankle-brachial pressure index can help identify vascular injury (7-8). Serial examinations and clear documentation are necessary.

Initial wound management involves removal of gross contamination, medical photography, then application of saline soaked gauze and an occlusive film. ${ }^{4}$ Intravenous antibiotics should be given ideally within one hour and tetanus prophylaxis should be administered (4). The limb should be realigned and splinted if necessary. Only at the time of surgery can the full extent of soft tissue damage be assessed, at which point open fractures can be graded as per the Gustilo-Anderson classification (9).

Realigning a deformed, pulseless limb often restores circulation (5). Active haemorrhage should be controlled with direct pressure and haemostatic dressings (10). Tourniquet application has also been shown to be beneficial, particularly when applied in the prehospital setting (11-12). If the limb is devascularised this requires urgent surgical intervention, which usually includes placement of a temporary intravascular shunt and skeletal stabilisation via external fixation (13). Following restoration of blood flow, the associated soft tissue injury can be addressed and definitive vascular reconstruction can be performed, either immediately or delayed depending on the clinical scenario (13). On-table angiography is also a useful means of assessing vascular injury (14).

The extent of peripheral nerve injuries must be clearly documented. If a nerve is found divided at surgery the ends should be opposed with fine, coloured sutures and its location must be recorded in the operation note (6). A surgeon experienced in peripheral nerve injuries should be contacted for advice as soon as possible.
A useful tool in the initial assessment of trauma patients is the computerised tomography (CT) scan. If the patient is stable and if clinically indicated a 'trauma CT' is often completed, which should produce a head-to-toe scannogram and can also include angiography to identify vascular injuries (4). Appropriate radiographs should be taken of injured extremities.

In patients with complex limb injuries clinicians should have a high index of suspicion for compartment syndrome (15). Clinical signs include pain out of proportion to the injury and pain on passive stretch of the involved compartment(s) (16). Later signs include paraesthesia, paralysis, pallor and absent pulses. Compartment syndrome requires emergent fasciotomy in line with BOAST guidance (16). Limb reperfusion can also lead to compartment syndrome and surgeons should consider prophylactic fasciotomies following restoration of circulation (17).

To aid with assessment and decision-making in complex limb trauma, scoring systems have been developed including the Mangled Extremity Severity Score (MESS) (18), Nerve Injury, Ischaemia, SoftTissue Injury, Skeletal Injury, Shock, and Age of Patient Score (NISSSA) (19), Predictive Salvage Index (PSI) (20), Limb Salvage Index (LSI) (21) and the Hannover Fracture Scale-97 (HFS97) (22). The utility of these systems is controversial and will be discussed later.

An important consideration in limb trauma is assessment of the patient as a whole. A detailed history must be taken, including past medical history, pre-injury functional status and social history. It is important to respect the patient's autonomy and also consult with their family.

\section{DECISION MAKING: LIMB SALVAGE VS AMPUTATION}

Decision making in complex limb injuries is difficult and must involve the patient, the family and the multidisciplinary team. One of the most challenging decisions when faced with a mangled limb is whether to attempt limb salvage or perform primary amputation. To aid with this decision, multiple scoring systems have been established. 
Perhaps the most widely known is the MESS (18). The MESS looks at degree of ischaemia, ischaemia time, age, shock and skeletal and soft tissue injury. The original MESS study in 1990 analysed 25 patients and concluded that a MESS greater that 7 predicted the need for amputation with $100 \%$ accuracy. Over the past 30 years this scoring system has been criticised. Loja et al. (23) point out that advances in surgical technique have lowered the accuracy of the MESS in predicting the need for amputation. O'Sullivan et al. (24) conclude that although it is a useful tool to predict outcome, it isn't accurate enough to be wholly relied upon.

The PSI was developed by Howe et al. (20) who report a sensitivity of $78 \%$ in predicting limb salvage, and a specificity of $100 \%$. However, this tool was analysed by Bosse et al. (25) using data from the Lower Extremity Assessment Project (LEAP) demonstrating a sensitivity of $40-56 \%$ and specificity of $79 \%$.

Bosse et al. (25) also analysed the MESS, NISSSA, PSI, LSI and HFS97 in 556 patients concluding that low scores may be used to predict limb salvage, but high scores do not necessarily predict the need for amputation. Schiro et al. (26) performed a systematic review of scoring systems and surmise that they are not useful in predicting functional outcome, or determining which patients benefit from amputation or limb salvage. Current National Institute for Health and Clinical Excellence (NICE) guidelines advise 'Do not base the decision whether to perform limb salvage or amputation on an injury severity tool score' (27).

To investigate factors involved in limb salvage versus amputation Song et al. (28) analysed GustiloAnderson grade 3C lower limb fractures, noting a $12 \%$ secondary amputation rate. They state that the commonest reason for secondary amputation is extensive soft tissue defect with muscle necrosis (28). Risk factors associated with this were complex fracture patterns, warm ischaemia time over 6 hours, development of compartment syndrome and MESS greater than 7. A similar study was conducted by Fochtmann et al. (29) with comparable findings in that muscle necrosis, soft tissue defect, soft tissue infection, associated vascular injury and fracture severity all predicted the need for secondary amputa- tion. Using data from the LEAP study, MacKenzie et al. (30) also agree that severe muscle and soft tissue injury predict the need for amputation. Additionally, MacKenzie et al. (30) demonstrated that both lower socioeconomic status and alcohol consumption are linked with need for amputation; albeit with lower odds ratios than extent of soft tissue injury. The data from MacKenzie et al. (30) also suggested that absent plantar sensation at the time of initial assessment is a predictor for amputation, however further research has disputed this, showing that nerve function often returns following reconstruction and that functional outcome is the same when compared to primary amputation $(31,32)$.

NICE guidelines advocate emergency amputation in life-saving circumstances, such as for uncontrollable life-threatening haemorrhage (27). In non-life-threatening situations, current guidance advises that a delayed primary amputation should be performed within 72 hours (4). NICE and BOAST guidelines highlight the importance of a multidisciplinary assessment including orthoplastics, rehabilitation specialists and patient and family involvement $(4,27)$. In practice patients often undergo immediate limb stabilisation with restoration of blood flow, and are then monitored closely and resuscitated on the intensive care unit for a short period. This period allows for a multidisciplinary assessment of limb viability, and gives time to discuss the options with the patient and family.

Advances in microsurgery techniques means that soft tissue reconstruction is becoming more attractive and widely available (33-35), however it is important to remember than not all cases are clear cut. Given the complexity of the decision to amputation or attempt limb salvage, scoring systems should be used only as a guide; instead more emphasis should be placed on the experience of the multidisciplinary team, and if possible, allowing the patient to make an informed decision (36).

\section{OUTCOMES: LIMB SALVAGE VS AMPUTATION}

Complex limb injuries represent significant trauma and have both a physical and psychological 
impact on patients and families. Clearly there are multiple variables that can affect outcome; including patient factors, injury patterns and treatment modalities.

As part of the LEAP study, Bosse et al. (37). identified factors that predicted poor outcome, measured by the Sickness Impact Profile (SIP), in patients who underwent limb salvage or amputation for high energy lower limb trauma. Poor outcome was associated with need for rehospitalisation due to complications, poor education, low socioeconomic status, non-white ethnicity, no medical insurance, poor social-support network, low self-efficacy, smoking and being involved in a compensation claim (37). These predictors of poor outcome were similar in the limb salvage and amputation groups. It must be noted that this was a US study and some factors may not be transferrable to other nations.

With regards to amputation versus limb salvage, there is conflicting literature surrounding which treatment has the most favourable outcome. Bosse et al. (37). demonstrated that at two years there is no significant difference in SIP, functional outcome or return to work. Nevertheless, both treatment modalities had over $40 \%$ of patients who scored greater than ten on the SIP, which represents severe disability. The only outcomes that differed were that patients who had amputations returned to theatre on average less than those who had limb salvage (5 vs 19.1 respectively), and also had less rehospitalisations. Penn-Barwell et al. (38) failed to find a difference at four years between limb salvage patients and amputees with respect to pain and shortfrom 36 scores (physical and mental components). Similar short-form 36 scores were demonstrated recently by Frisvoll et al., who also reported no difference in patient satisfaction scores (39).

Akula et al. (40) performed a meta-analysis comparing amputation versus limb salvage concluding that there was no significant difference in physical morbidity, however they identified that patients who underwent limb salvage had greater psychological outcomes. Ladlow et al. (41) also assessed mental health outcomes, in the form of depression and anxiety questionnaires in military personnel, this time identifying no difference between limb salvage and amputation. Ladlow et al. (41) found that immediate amputation was more favourable than limb salvage in terms of functional outcome, as measured by ability to run independently and sixminute walking distance. The benefits of amputation were also noted by Fioravanti et al. (42) who report reduced infections and revision procedures, shorter length of stay, improved quality of life and return to physical activity. Similar to Bosse et al. (37) they found no difference in return to work.

The mangled extremity is often associated with traumatic brain injury, which clearly impacts not only outcome, but also patient involvement in the decision-making process (43). This issue is perhaps more common in lower limb injuries than upper limb injuries, as the mangled upper extremity is more frequently an isolated injury, such as in industrial trauma for example.

Looking at upper limb injuries only, Mitchell et al. (44) demonstrated no significant difference in physical or psychological outcomes comparing salvage to amputation. They conclude that emphasis should be placed on treating post-traumatic stress disorder, depression, chronic pain and health habits to help reduce morbidity (44). Ellington et al. (45) looked at the mangled foot and ankle, noting that patients treated with amputation had greater twoyear outcomes compared to those treated with free flaps and/or ankle arthrodesis. The OUTLET trial is currently ongoing which aims to compare salvage versus amputation in distal tibia, foot and/or ankle trauma (46).

Given the variable outcomes and treatment modalities in complex limb injuries it is important that clinicians encourage patients and families to be involved in the decision-making process as much as possible. Chung et al. (47) performed a decision analysis in physicians and patients looking at estimated quality-adjusted life years following amputation or salvage. This demonstrated that patients clearly favour reconstruction, whereas clinicians only slightly favoured reconstruction. As there is little literature that supports reconstruction as a superior treatment option, it is essential when discussing treatment options that clinicians acknowledge patients' expectations and give them the required information to make an informed decision. It is important that patients understand that 
amputation isn't necessarily a failure of treatment (48).

\section{CONCLUSION}

Complex limb injuries are a significant challenge both for patients and the treating clinician. Initial assessment involves using a systematic approach, saving life before limb, with early involvement of the relevant surgical specialities and multidisciplinary team. The decision to attempt limb salvage or perform amputation can be extremely difficult. Scoring systems can be used as a guide but should not be wholly relied upon; instead more emphasis should be placed on the surgeon's experience, extent of soft tissue damage, and patient factors and wishes. Outcomes following amputation versus limb salvage are comparable, with some studies suggesting amputation may be favourable. Ultimately a clinician's role is to advise patients and families on what treatment may be in their best interest, and give as much information as possible so they can make an informed decision on what is undoubtably a life changing event.

\section{REFERENCES}

1. Prasarn ML, Helfet DL, Kloen P. Management of the mangled extremity. Strategies Trauma Limb Reconstr. 2012; 7(2): 57-66.

2. Patel MB, Richter KM, Shafi S. Mangled Extremity: Amputation Versus Salvage. Curr Trauma Rep. 2015; 1(1): 45-49.

3. ATLS Subcommittee, American College of Surgeons' Committee on Trauma, International ATLS working group. Advanced trauma life support (ATLS®): the ninth edition. J Trauma Acute Care Surg. 2013; 74(5): 1363-1366.

4. British Orthopaedic Association Audit Standards for Trauma (BOAST). Open fractures [internet]. 2017 [cited 16/2/20]. Available from: https://www.boa.ac.uk/standardsguidance/boasts.html

5. British Orthopaedic Association Audit Standards for Trauma (BOAST). Management of arterial injuries [internet]. 2014 [cited 16/2/20]. Available from: https:// www.boa.ac.uk/standards-guidance/boasts.html

6. British Orthopaedic Association Audit Standards for Trauma (BOAST). Peripheral nerve injury [internet]. 2012 [cited 16/2/20]. Available from: https://www.boa. ac.uk/standards-guidance/boasts.html

7. Kurtoğlu M, Dolay $K$, Karamustafaoğlu $B$, Karamustafaoglu B, Yanar H, Kuzkaya M. The role of the ankle brachial pressure index in the diagnosis of peripheral arterial injury. Ulus Travma Acil Cerrahi Derg. 2009; 15(5): 448-452.

8. Peck MA, Rasmussen TE. Management of blunt peripheral arterial injury. Perspect Vasc Surg Endovasc Ther. 2006; 18(2): 159-173.

9. Gustilo RB, Anderson JT. Prevention of infection in the treatment of one thousand and twenty-five open fractures of long bones: retrospective and prospective analyses. J Bone Joint Surg Am. 1976; 58(4): 453-458.

10. Drew B, Bennett BL, Littlejohn L. Application of current hemorrhage control techniques for backcountry care: part one, tourniquets and hemorrhage control adjuncts. Wilderness Environ Med. 2015; 26(2): 236-245.

11. Inaba K, Siboni S, Resnick S, et al. Tourniquet use for civilian extremity trauma. J Trauma Acute Care Surg. 2015; 79(2): 232-237; quiz 332-333.

12. Teixeira PGR, Brown CVR, Emigh B, et al. Civilian Prehospital Tourniquet Use Is Associated with Improved Survival in Patients with Peripheral Vascular Injury. $J$ Am Coll Surg. 2018; 226(5): 769-776.e1.

13. Wlodarczyk JR, Thomas AS, Schroll R, et al. To shunt or not to shunt in combined orthopedic and vascular extremity trauma. J Trauma Acute Care Surg. 2018; 85(6): 10381042.

14. Callcut RA, Acher CW, Hoch J, Tefera G, Turnipseed W, Mell MW. Impact of intraoperative arteriography on limb salvage for traumatic popliteal artery injury. J Trauma. 2009; 67(2): 252-257; discussion 257-258.

15. McQueen MM, Gaston P, Court-Brown CM. Acute compartment syndrome. Who is at risk? J Bone Joint Surg Br. 2000; 82(2): 200-203.

16. British Orthopaedic Association Audit Standards for Trauma (BOAST). Diagnosis and Management of Compartment Syndrome of the Limbs [internet]. 2014 [cited 16/2/20]. Available from: https://www.boa.ac.uk/standardsguidance/boasts.html

17. Farber A, Tan TW, Hamburg NM, et al. Early fasciotomy in patients with extremity vascular injury is associated with decreased risk of adverse limb outcomes: a review of the National Trauma Data Bank. Injury. 2012; 43(9): 14861491.

18. Johansen K, Daines M, Howey T, Helfet D, Hansen Jr ST. Objective criteria accurately predict amputation following lower extremity trauma. J Trauma. 1990; 30(5): 568-572; discussion 572-573.

19. McNamara MG, Heckman JD, Corley EG. Severe open fracture of the lower extremity: a retrospective evaluation of the Mangled Extremity Severity Score. J Orthop Trauma. 1994; 8: 81-87.

20. Howe HR Jr, Poole GV Jr, Hansen KJ, et al. Salvage of lower extremities following combined orthopedic and vascular trauma. A predictive salvage index. Am Surg. 1987; 53(4): 205-208.

21. Russell WL, Sailors DM, Whittle TB, Fisher DF Jr, Burns RP. Limb salvage versus traumatic amputation. A 
decision based on a seven-part predictive index. Ann Surg. 1991; 213: 473-481.

22. Tscherne H, Oestern HJ. A new classification of soft-tissue damage in open and closed fractures. Unfallheilkunde. 1982; 85: 111-115.

23. Loja MN, Sammann A, DuBose J, et al. The mangled extremity score and amputation: Time for a revision. $J$ Trauma Acute Care Surg. 2017; 82(3): 518-523.

24. O'Sullivan ST, O'Sullivan M, Pasha N, O'Shaughnessy M, O'Connor PF. Is it possible to predict limb viability in complex Gustilo IIIB and IIIC tibial fractures? A comparison of two predictive indices. Injury. 1997; 28(910): 639-642.

25. Bosse MJ, MacKenzie EJ, Kellam JF, et al. A prospective evaluation of the clinical utility of the lower-extremity injury-severity scores. J Bone Joint Surg Am. 2001; 83(1): 3-14.

26. Schirò GR, Sessa S, Piccioli A, Maccauro G. Primary amputation vs limb salvage in mangled extremity: a systematic review of the current scoring system. $B M C$ Musculoskelet Disord. 2015; 16: 372.

27. National Institute for Health and Clinical Excellence (NICE). Fractures (complex): assessment and management (Nice guidance 37) [internet]. 2016 [cited 16/2/20]. Available from: http://nice.org.uk/guidance/ng37

28. Song W, Zhou D, Dong J. Predictors of secondary amputation in patients with grade IIIC lower limb injuries: A retrospective analysis of 35 patients. Medicine (Baltimore). 2017; 96(22): e7068.

29. Fochtmann A, Mittlböck M, Binder H, Kottstorfer J, Hajdu S. Potential prognostic factors predicting secondary amputation in third-degree open lower limb fractures. $J$ Trauma Acute Care Surg. 2014; 76(4): 1076-1081.

30. MacKenzie EJ, Bosse MJ, Kellam JF, et al. Factors influencing the decision to amputate or reconstruct after high-energy lower extremity trauma. J Trauma. 2002; 52(4): 641-649.

31. Bosse M, McCarthy Ml, Jones Al, et al. The insensate foot following severe lower extremity trauma: an indication for amputation? J Bone Joint Surg Am. 2005; 87(12): 26012608.

32. Momoh AO, Kumaran S, Lyons D, et al. An Argument for Salvage in Severe Lower Extremity Trauma with Posterior Tibial Nerve Injury: The Ganga Hospital Experience. Plast Reconstr Surg. 2015; 136(6): 1337-1352.

33. Bolletta A, Corrado R, Chen HC. Advances in microsurgery for upper and lower extremity reconstruction and limb preservation. Plast Aesthet Res. 2019 Oct; 6: 22.

34. Kadam D. Limb salvage surgery. Indian J Plast Surg. 2013; 46(2): 265-274.

35. Korompilias AV, Lykissas MG, Vekris MD, Beris AE, Soucacos PN. Microsurgery for lower extremity injuries. Injury. 2008; 39 Suppl 3: S103-S108.
36. Korompilias AV, Beris AE, Lykissas MG, Verkis MD, Kontogeorgakos VA, Soucacos PN. The mangled extremity and attempt for limb salvage. J Orthop Surg Res. 2009; 4: 4.

37. Bosse MJ, MacKenzie EJ, Kellam JF, et al. An analysis of outcomes of reconstruction or amputation after legthreatening injuries. N Engl J Med. 2002; 347: 1924-1931.

38. Penn-Barwell JG, Myatt RW, Bennett PM, Sargeant ID. Medium-term outcomes following limb salvage for severe open tibia fracture are similar to trans-tibial amputation. Injury. 2015; 46(2): 288-291.

39. Frisvoll C, Clarke-Jenssen J, Madsen JE, et al. Longterm outcomes after high-energy open tibial fractures: Is a salvaged limb superior to prosthesis in terms of physical function and quality of life? Eur J Orthop Surg Traumatol. 2019; 29(4): 899-906.

40. Akula M, Gella S, Shaw CJ, McShane P, Mohsen AM. A meta-analysis of amputation versus limb salvage in mangled lower limb injuries - The patient perspective. Injury. 2011; 42(11): 1194-1197.

41. Ladlow P, Phillip R, Coppack R, et al. Influence of Immediate and Delayed Lower-Limb Amputation Compared with Lower-Limb Salvage on Functional and Mental Health Outcomes Post-Rehabilitation in the U.K. Military. J Bone Joint Surg Am. 2016; 98(23): 1996-2005.

42. Fioravanti M, Maman P, Curvale G, Rochwerger A, Mattei J-C. Amputation versus conservative treatment in severe open lower-limb fracture: A functional and qualityof-life study. Orthop Traumatol Surg Res. 2018; 104(2): 277-281.

43. Kushwaha VP, Garland DG. Extremity fractures in the patient with a traumatic brain injury. J Am Acad Orthop Surg. 1998; 6(5): 298-307.

44. Mitchell SL, Hayda R, Chen AT, Carlini AR, Ficke JR, MacKenzie EJ. The Military Extremity Trauma Amputation/Limb Salvage (METALS) Study: Outcomes of Amputation Compared with Limb Salvage Following Major Upper-Extremity Trauma. J Bone Joint Surg Am. 2019; 101(16): 1470-1478.

45. Ellington JK, Bosse MJ, Castillo RC, MacKenzie EJ. The mangled foot and ankle: results from a 2-year prospective study. J Orthop Trauma. 2013; 27(1): 43-48.

46. Bosse MJ, Teague D, Reider L, et al. Outcomes After Severe Distal Tibia, Ankle, and/or Foot Trauma: Comparison of Limb Salvage Versus Transtibial Amputation (OUTLET). J Orthop Trauma. 2017; 31 Suppl 1: S48-S55.

47. Chung KC, Shauver MJ, Saddawi-Konefka D, Haase SC. A decision analysis of amputation versus reconstruction for severe open tibial fracture from the physician and patient perspectives. Ann Plast Surg. 2011; 66(2): 185-191.

48. van Dongen TT, Huizinga EP, de Kruijff LG, et al. Amputation: Not a failure for severe lower extremity combat injury. Injury. 2017; 48(2): 371-377. 